\title{
Evaluation of chilled and frozen-thawed canine spermatozoa using a zona pellucida binding assay
}

\author{
B. Ström Holst, B. Larsson, C. Linde-Forsberg* and H. Rodriguez-Martinez \\ Department of Obstetrics and Gynaecology, Faculty of Veterinary Medicine, Centre for Reproductive Biology in Uppsala, \\ Swedish University of Agricultural Sciences (SLU), Box 7039, SE-750 07 Uppsala, Sweden
}

\begin{abstract}
Zona pellucida binding assays provide information about the fertilizing ability of spermatozoa. A zona-binding assay for canine spermatozoa using intact, denuded homologous oocytes has not been evaluated previously. In the present study, an assay using canine oocytes derived from frozen-thawed ovaries was evaluated using three types of semen: fresh untreated; killed; and a 50:50 mixture of untreated and killed spermatozoa. The assays were performed on $3 \times 20$ oocytes for each sperm treatment, using semen from pooled ejaculates $\left(0.5 \times 10^{6}\right.$ spermatozoa in each $50 \mu \mathrm{l}$ droplet containing five oocytes). There was a significant difference $(P<0.001)$ between all treatments. Thereafter, the same procedure was used to evaluate methods of chilling and freeze-thawing of canine semen. There was a trend $(P=0.067)$ for more sperm binding after 1 day of chilling compared with after 4 days of chilling. Semen samples frozen using an extender (with or without the addition of Equex STM paste) were evaluated. Equex had a significant $(P=0.034)$ positive effect on the capacity of the spermatozoa to bind to the zona pellucida. In conclusion, the addition of a zona pellucida binding assay to established in vitro tests should give a better estimate of the damage caused by the various procedures when developing new techniques for chilling and freeze-thawing. Furthermore, the present study showed that chilling for 4 days tended to reduce the zona-binding capacity of the spermatozoon, and that Equex STM paste had a beneficial effect on the capacity of the frozen-thawed spermatozoon to bind to the zona pellucida.
\end{abstract}

\section{Introduction}

When the fertility of a semen sample in vivo is predicted using in vitro methods, a combination of different tests usually gives more reliable results than one test alone (Amann, 1989; Zhang et al., 1998, 1999). The reason for this is that a combination of tests measuring different aspects of sperm function provides information about several different sperm characteristics required for fertilization. These functions should be vital to the fertilizing ability of the spermatozoa. In addition, the evaluated sperm function should vary among the sperm populations evaluated, and the intra-assay variation should be smaller than the variation among the sperm populations.

The acrosome and plasma membrane are damaged after chilling (for example, see Rota et al., 1995) and freezethawing (for example, see Rota et al., 1997; Ström et al., 1997; Ström Holst et al., 1998) of dog semen. The addition of the detergent Equex STM paste to the freezing extender has been found to increase significantly the proportion of

${ }^{*}$ Correspondence and reprint requests.

Received 15 September 1999. spermatozoa with an intact plasma membrane after freezethawing (Rota et al., 1997; A. Peña and C. Linde-Forsberg, in press). Damage to associated molecular binding structures cannot be detected using routine morphological techniques. Therefore, the ability of the spermatozoon to bind to the zona pellucida is a potentially valuable test when evaluating techniques for chilling and freeze-thawing semen. Another advantage of using gamete interaction tests is that they account for several sperm parameters. Therefore, these tests have been used to evaluate sperm function in several species. Tests to evaluate the ability of spermatozoa to bind to the zona pellucida or hemi-zona pellucida have been developed for bovine (Fazeli et al., 1993a), equine (Fazeli et al., 1993b) and pig (Fazeli et al., 1995) species.

A sperm-oocyte interaction test for the canine species has been described (Hay et al., 1997a) in which the sperm suspension is incubated with fresh, intact oocytes surrounded by cumulus cells. After $18 \mathrm{~h}$, the number of spermatozoa that had penetrated the oocytes is counted. This test is useful for evaluating both chilled and frozen-thawed semen. Canine oocytes can be obtained from ovaries removed at ovariohysterectomy, but the number of oocytes recovered varies greatly among bitches and is difficult to predict 
(B. Ström Holst, B. Larsson, H. Rodriguez-Martinez, A-S. Lagerstedt and C. Linde-Forsberg, unpublished). As a result, different regimens for storing oocytes have been investigated. The use of salt-stored oocytes surrounded by cumulus cells was unsuccessful in a study that used the zona pellucida binding-penetration assay in dogs (Hay et al., 1997b). However, it was not established whether this was due to changes in the zona pellucida or in the cumulus cells.

Frozen oocytes from previously frozen ovaries have been used for a hemi-zona pellucida-binding assay, and the results indicate that this test can be used to differentiate between fertile and infertile dogs (Mayenco-Aguirre and Pérez Cortés, 1998). A hemi-zona pellucida-binding assay using frozen, in vitro matured oocytes has also been used for evaluating the post-thaw fertilizing ability of canine spermatozoa (Ivanova et al., 1999). However, the hemi-zona pellucida-binding assay is a time-consuming test and its use in humans has recently been questioned, as the sperm-binding capacity of oocytes is unevenly distributed (Magerkurth et al., 1999), that is, the two halves of an oocyte do not have an equivalent sperm binding capacity (which is the basic assumption of the hemi-zona pellucida-binding assay). Deep-freezing of canine ovaries has been shown to constitute a possible source of canine oocytes when ovariohysterectomies are performed at irregular intervals (Ström Holst et al., 1999). Furthermore, deep-freezing of ovaries has the advantage that the potential number of oocytes recovered from an ovary can be predicted after removal of oocytes from the other ovary of the same bitch (B. Ström Holst, B. Larsson, H. Rodriguez-Martinez, A-S. Lagerstedt and C. Linde-Forsberg, unpublished). There is a large variation in sperm-binding capacity among oocytes (Ström Holst et al., 1999), which may be attributed in part to the stickiness of the canine zona pellucida, which is why the zona pellucida-binding assay for the estimation of canine sperm function has to be evaluated.

The aim of the present study was to evaluate a zona pellucida-binding assay for canine spermatozoa using intact, homologous, denuded oocytes recovered from frozen-thawed ovaries. Comparisons were made between untreated and killed spermatozoa, and a 50:50 mixture of untreated and killed spermatozoa, between semen chilled for 1 or 4 days, and between semen frozen using one extender with Equex STM paste and one extender without.

\section{Materials and Methods}

\section{Semen collection and evaluation}

Semen was collected twice from three dogs, a 3-year-old Briard, a 4-year-old German shepherd and a 7-year-old of mixed breed, each with a sperm motility of $\geqslant 75 \%$ and $<20 \%$ sperm defects, as estimated subjectively using a phasecontrast microscope at $\times 400$ magnification. Sperm concentration was measured using a photometer (Spermacue ${ }^{\circledR}$, Minitüb, Tiefenbach). On both occasions, the semen was pooled. The first pooled sample was used for Expt 1 and the second pooled sample was used for Expts 2 and 3.

\section{Oocyte recovery}

Ovaries were obtained from 21 bitches subjected to ovariohysterectomy. The bitches were of 19 different breeds and two mixed breeds and their mean age was 8.5 years $(\mathrm{SD}=2.1)$. Three of the bitches had follicles as the only visible structure on the ovarian surface, eight had corpora lutea only, nine had follicles and corpora lutea, and one bitch had no visible structures on the ovarian surface. The ovaries were washed with PBS, frozen in $20 \mathrm{ml} \mathrm{NaCl}$ and then stored at $-20^{\circ} \mathrm{C}$ until thawing at room temperature. After thawing, the cumulus-oocyte complexes were recovered by repeated slicing of the ovaries at intervals of approximately $1 \mathrm{~mm}$, and then dicing of these slices, again with intervals of approximately $1 \mathrm{~mm}$, in a Petri dish with PBS and 0.5\% (w/v) BSA under a stereomicroscope. The cumulus cells were removed by incubating the oocytes in $75 \mathrm{mmol}$ sodium citrate $\mathrm{l}^{-1}$ for $15 \mathrm{~min}$, whereupon they were vortexed (VortexGenie 2, Labora, Sollentuna) for 15 min (Mahi-Brown, 1991). The oocytes were then stored overnight at $4^{\circ} \mathrm{C}$ in PBS with $0.5 \%(\mathrm{w} / \mathrm{v}) \mathrm{BSA}$, and used the following day for a zona pellucida-binding assay.

\section{Zona pellucida binding assay}

For the sperm-zona binding, $10 \mu \mathrm{l}$ droplets of canine capacitation medium (CCM) (Mahi and Yanagimachi, 1978), without antibiotics were prepared in Petri dishes $(35 \times 10$ $\mathrm{mm}$ ), and covered with $3 \mathrm{ml}$ mineral oil. Five oocytes were added to each droplet, whereupon the oocytes were incubated in $5 \% \mathrm{CO}_{2}$ in humidified air at $37^{\circ} \mathrm{C}$ for a minimum of $1 \mathrm{~h}$ for equilibration. Thereafter, $40 \mu \mathrm{l}$ of the sperm suspension was added to each droplet, making the final concentration $0.5 \times 10^{6}$ spermatozoa $\mathrm{ml}^{-1}$ in a $50 \mu \mathrm{l}$ droplet. The droplets containing oocytes and spermatozoa were co-incubated in 5\% $\mathrm{CO}_{2}$ in humidified air at $37^{\circ} \mathrm{C}$ for $6 \mathrm{~h}$. Thereafter, the oocytes were removed from the incubation medium, fixed for $15 \mathrm{~min}$ in $1.5 \%(\mathrm{v} / \mathrm{v})$ glutaraldehyde in $0.067 \mathrm{~mol}$ sodium cacodylate buffer $1^{-1}$, and stored in PBS with $0.5 \%(\mathrm{w} / \mathrm{v})$ BSA until evaluation. The sperm-oocyte complexes were washed after storing by pipetting ten times in a $100 \mu$ d droplet of PBS using a pipette with a diameter only slightly bigger than the oocyte $(0.1-0.2 \mathrm{~mm})$ to remove loosely attached spermatozoa. The sperm-oocyte complexes were stained for $15 \mathrm{~min}$ with a solution of $20 \mu \mathrm{l}$ propidium iodide in $1000 \mu \mathrm{l}$ PBS with BSA. For evaluation, oocytes were placed on a slide and overlaid with a coverslip supported by four droplets of a vaselineparaffin mixture (1:3). Pressure was applied on each droplet to secure the oocyte and to lightly compress it onto the slide. The number of spermatozoa that had bound to the zona was counted using epifluorescence UV illumination on a Leitz Dialux 20 (Wetzlar) microscope. Observations were made at a magnification of $\times 400$.

\section{Experiment 1. Control: untreated-killed spermatozoa}

Semen was collected and ejaculates were pooled as described above. The pooled semen had a volume of $6 \mathrm{ml}$, 
$80 \%$ sperm motility and a total of $1980 \times 10^{6}$ spermatozoa. The semen was washed using Percoll density gradient fractionation and $1 \mathrm{ml}$ semen was gently poured on top of a Percoll column ( $1 \mathrm{ml} 80 \%(\mathrm{v} / \mathrm{v})$ and $1 \mathrm{ml} 40 \%(\mathrm{v} / \mathrm{v})$ isoosmotic Percoll in CCM), and centrifuged for $30 \mathrm{~min}$ at $400 \mathrm{~g}$. After centrifugation, the pellets were resuspended in CCM to make a total volume of $10 \mathrm{ml}$, and the suspension was then divided into halves. The motility after washing with Percoll was $50 \%$. Half of the spermatozoa were killed by plunging the test tube directly into liquid nitrogen three times and each time thawing the suspension in a $90^{\circ} \mathrm{C}$ waterbath. No spermatozoa were motile after this treatment. Half of the killed sperm suspension was then mixed with half of the untreated suspension, making three groups: untreated spermatozoa: a 50:50 mixture of killed and untreated spermatozoa; and killed spermatozoa. The sperm concentration was determined for each group by manual counting using a haemocytometer (Bürker chamber; Bane, 1952) and the suspensions were diluted with CCM to a final concentration of $0.625 \times 10^{6}$ spermatozoa $\mathrm{ml}^{-1}$. A zona pellucida-binding assay was carried out as described above, using $3 \times 20$ oocytes derived and pooled from nine bitches for each group.

\section{Experiment 2. Semen chilled for 1 or 4 days}

Semen was collected and ejaculates were pooled as described above. The pooled semen had a volume of $12 \mathrm{ml}$, $85 \%$ sperm motility and a total of $1890 \times 10^{6}$ spermatozoa. Half of the pooled sample was used as chilled semen in Expt 2, and half as frozen semen in Expt 3.

For chilling, the semen was first centrifuged for $6 \mathrm{~min}$ at $700 \mathrm{~g}$. The pellet was resuspended in a tris-citric acid-fructose extender with $20 \%$ (v/v) egg yolk (Rota et al., $1995)$ to a concentration of $100 \times 10^{6}$ spermatozoa $\mathrm{ml}^{-1}$. The extended semen was placed in a cooler, where it reached $4^{\circ} \mathrm{C}$ in about $45 \mathrm{~min}$, and was then stored at $4^{\circ} \mathrm{C}$ for 1 or 4 days.

On day 1 and day 4, $1 \mathrm{ml}$ extended semen was removed and warmed to room temperature. It was then cleansed using Percoll density-gradient fractionation, as for Expt 1. Subjective motility on day 1 was $75 \%$ before and $60 \%$ after washing with Percoll; on day 4 motility was $60 \%$ before and $55 \%$ after Percoll centrifugation. The pellet was resuspended in CCM to a concentration of $0.625 \times 10^{6}$ spermatozoa $\mathrm{ml}^{-1}$. A zona pellucida-binding assay was carried out as described above, using $3 \times 20$ oocytes for each semen treatment group. The oocytes were derived and pooled from six bitches so that, from the same bitch, oocytes from one ovary were used to test semen on day 1, and oocytes from the other ovary were used for testing semen on day 4 , making a total of 120 oocytes evaluated.

\section{Experiment 3. Semen frozen using a tris-citric acid-glucose extender, with or without Equex STM paste}

Half of the pool collected for Expt 2 was divided into two parts and centrifuged for $6 \mathrm{~min}$ at $700 \mathrm{~g}$. The two pellets were resuspended in a tris-citric acid-glucose extender containing 20\% (v/v) egg yolk and 3\% (v/v) glycerol (Rota et al., 1997) (EYT-G) to a concentration of $200 \times 10^{6}$ spermatozoa $\mathrm{ml}^{-1}$, placed in a cooler and chilled to $4^{\circ} \mathrm{C}$. After $1 \mathrm{~h}$, an equal amount of a second extender was added to each of the diluted semen samples, with the same composition as described above, except for the glycerol concentration, which was now $7 \%(v / v)$. Equex STM paste (1\% (v/v); Nova Chemical Sales, Scituate, Inc., MA) was added to one of the two samples. The extended semen was frozen in $0.5 \mathrm{ml}$ straws by lowering them in three steps into a liquid nitrogen tank (Rota et al., 1997).

For the zona pellucida-binding assay, three straws from each treatment were thawed in a waterbath at $38^{\circ} \mathrm{C}$ for $1 \mathrm{~min}$. Each straw was then emptied into a separate test tube and kept at $38^{\circ} \mathrm{C}$ for $5 \mathrm{~min}$. Motility was 65,70 and $65 \%$ for the three straws containing extender with Equex STM paste (EYT-GE) and 65, 65 and $65 \%$ for the three straws containing extender without Equex STM paste (EYT-G). The spermatozoa were washed using Percoll density-gradient fractionation, as for Expt 1, except that smaller volumes were used $(0.4 \mathrm{ml}$ semen poured on top of $0.4 \mathrm{ml} 80 \%$ and $0.4 \mathrm{ml} 40 \%$ iso-osmotic Percoll in CCM). The pellets were resuspended in CCM, motility was reassessed and found to be 70, 65 and 50\% with EYT-GE and 70, 70 and $65 \%$ with EYT-G. The samples were diluted to a final concentration of $0.625 \times 10^{6}$ spermatozoa $\mathrm{ml}^{-1}$, whereupon they were subjected to a zona pellucida-binding assay as described above. Each semen sample was evaluated using 20 oocytes from a pool from six bitches. The same bitches were used for both treatments, with the oocytes from one ovary included in a pool for the evaluation of semen frozen with EYT$\mathrm{GE}$, and the oocytes from the other ovary were used for semen frozen with EYT-G. A total of 120 oocytes was evaluated.

\section{Statistical analysis}

The effect of the treatment on the number of spermatozoa bound to each oocyte was evaluated with a generalized least squares analysis using the mixed procedure in the SAS statistical package (SAS version 6.12, SAS Institute Inc., Cary, NC). The square root of the number of spermatozoa bound was used as the response variable so that the random components would be normally distributed. The fixed part of the model was treatment $(\alpha)$ with three or two levels, and the random part was replicates within treatments $(r)$ and residuals $(e)$. The random components were assumed to be independent and normally distributed, and this assumption was checked by box-plots and an extension of Shapiro and Wilk's test (Royston, 1982). The model was:

$$
y_{\mathrm{ijk}}=\mu+\alpha_{\mathrm{i}}+r_{\mathrm{ij}}+e_{\mathrm{ijk}}
$$

Where $i=$ index for treatments $(1,2$ or $1,2,3) ; j=$ relicate within treatment; and $k=$ measurements within replicate. Values were given in the transformed scale that belongs to the analysis. Back-transformed values on the mean number of bound spermatozoa were also presented for clarity. The level of statistical significance was set at $P<0.05$. 


\section{Results}

\section{Experiment 1}

The spermatozoa bound to zona pellucida usually were quite evenly distributed, although both in the untreated group and, in the 50:50 killed:untreated group, they occasionally bound in clusters. The variation between replicates within treatment was small (Table 1) and there was a significant difference among all treatments in the number of bound spermatozoa (untreated group: 19.1, 50:50 killed:untreated group: 7.7, killed group: 0.06) (Table 2).

\section{Experiment 2}

The number of spermatozoa bound on day 1 (4.8) and day 4 (0.9) did not differ significantly, although there was a trend $(P=0.067)$ for decreased sperm binding after 4 days. Both the variation between and within replicates was higher than in Expts 1 and 3 (Table 3).

\section{Experiment 3}

Significantly more spermatozoa bound to the zona pellucida when treated with EYT-GE than with EYT-G $(P<0.05)$ (Table 3). The spermatozoa were evenly bound to the zona pellucida, except for one oocyte incubated with semen treated with EYT-GE, on which clusters were observed.

\section{Discussion}

Evaluation of sperm function using zona pellucida-binding assay has been developed for several species (for example, see Fazeli et al., 1993a,b, 1995; Franken et al., 1993; Goodrowe and Hay, 1993). The zona pellucida-binding assay measures

Table 1. Effect of canine sperm treatment (Expt 1 ) on the capacity to bind to the zona pellucida (ZP)

\begin{tabular}{lccccc}
\hline & \multicolumn{2}{c}{$\begin{array}{c}\text { Number of spermatozoa bound } \\
\text { to the zona pellucida }\end{array}$} & & & \\
\cline { 2 - 3 } $\begin{array}{l}\text { Sperm } \\
\text { treatment }\end{array}$ & $\begin{array}{c}\text { Back-transformed from } \\
\text { square roots (LSM) }\end{array}$ & $\begin{array}{c}\text { Square roots } \\
\text { (LSM) }\end{array}$ & SEM & $\begin{array}{c}\text { Variation between replicates } \\
\text { within treatment }\end{array}$ & $\begin{array}{c}\text { Variation within } \\
\text { replicates }\end{array}$ \\
\hline Untreated & 19.1 & 4.4 & 0.18 & & \multirow{2}{*}{0.0} \\
$50 \%$ killed & 7.7 & 2.3 & 0.18 & & \\
$100 \%$ killed & 0.056 & 0.24 & 0.17 & & \\
\hline
\end{tabular}

${ }^{*}$ Calculated from square roots.

LSM: least squares means.

Table 2. Comparisons of canine sperm treatments (Expt 1 )

\begin{tabular}{lccc}
\hline Treatments compared & Difference between LSMs* & SD & $P$ value \\
\hline Untreated versus 50\% killed & 1.6 & 0.25 & 0.0007 \\
$50 \%$ killed versus 100\% killed & 2.5 & 0.25 & 0.0001 \\
Untreated versus 100\% killled & 4.1 & 0.25 & 0.0001 \\
\hline
\end{tabular}

${ }^{*}$ Calculated from square roots.

LSM: least squares means.

Table 3. Number of canine spermatozoa bound to the zona pellucida, and comparisons between treatments, between chilled (Expt 2) and frozen-thawed (Expt 3) spermatozoa

\begin{tabular}{|c|c|c|c|c|c|c|c|c|}
\hline \multirow[b]{2}{*}{$\begin{array}{l}\text { Sperm } \\
\text { treatment }\end{array}$} & \multicolumn{2}{|c|}{$\begin{array}{c}\text { Number of spermatozoa bound } \\
\text { to the zona pellucida }\end{array}$} & \multirow[b]{2}{*}{ SEM } & \multirow[b]{2}{*}{$\begin{array}{c}\text { Difference } \\
\text { between LSMs* }\end{array}$} & \multirow[b]{2}{*}{ SD } & \multirow[b]{2}{*}{$P$ value } & \multirow[b]{2}{*}{$\begin{array}{l}\text { Variation between replicates } \\
\text { within treatment* }\end{array}$} & \multirow[b]{2}{*}{$\begin{array}{l}\text { Variation within } \\
\text { replicates }\end{array}$} \\
\hline & $\begin{array}{l}\text { Back-transformed from } \\
\text { square roots (LSM) }\end{array}$ & $\begin{array}{l}\text { Square roots } \\
\text { (LSM) }\end{array}$ & & & & & & \\
\hline Chilled day 1 & 4.8 & 2.2 & 0.35 & 1.24 & 0.50 & 0.067 & 0.26 & 2.0 \\
\hline Chilled day 4 & 0.90 & 0.95 & 0.35 & & & & & \\
\hline Frozen EYT-GE & 3.0 & 1.7 & 0.26 & 1.15 & 0.37 & 0.034 & 0.14 & 1.2 \\
\hline Frozen EYT-G & 0.33 & 0.57 & 0.26 & & & & & \\
\hline
\end{tabular}

${ }^{*}$ Calculated from square roots.

LSM: least squares means; EYT-GE: extender with Equex STM paste; EYT-G: extender without Equex STM paste. 
the ability of spermatozoa to bind to oocytes. This binding is mediated through receptors at the sperm plasma membrane, and one or more zona pellucida glycoproteins (Yanagimachi, 1994). Therefore, a zona pellucida-binding assay would be expected to reveal damage that cannot be evaluated using routine microscopic techniques. The significant differences between untreated and killed spermatozoa demonstrated in the present study indicate that the binding of dog spermatozoa to the zona pellucida is a specific feature of living cells, and is not influenced to any great extent by, for example, the stickiness of the zona pellucida. In cattle, a correlation has been demonstrated between zona pellucida binding ability and fertility in vivo (Fazeli et al., 1997a; Zhang et al., 1998). Nevertheless, a lack of correlation between fertility in vivo and the ability of spermatozoa to bind to the zona pellucida indicates that this interaction is neither a limiting step in fertile boars (Berger et al., 1996) nor a useful estimator for assessing the fertility of cryopreserved ram spermatozoa (Codde and Berger, 1995). Therefore, although interaction between the spermatozoon and the zona pellucida is essential, the usefulness of a zona pellucidabinding assay cannot be taken for granted, and depends both on the species and on the type of sperm population to be evaluated. Differences in the sperm-zona pellucida binding ability between spermatozoa subjected to different chilling procedures (Hay et al., 1997a), and between the spermatozoa of fertile and infertile dogs (Mayenco-Aguirre and Pérez Cortés, 1998) indicate that, in dogs, a zona pellucida-binding assay can be used to evaluate not only damage caused by sperm storage, but also malfunctions in untreated spermatozoa causing decreased fertility.

In cattle, capacitation in vitro leads to an increased capacity of spermatozoa to bind to the zona pellucida (Topper et al., 1999). In humans, acrosome-reacted spermatozoa may have the capacity to associate loosely with the zona pellucida by a reversible attachment, whereas acrosome-intact spermatozoa may achieve irreversible binding (Franken, 1998). In pigs, acrosome-intact spermatozoa initiate binding to the zona pellucida (Fazeli et al., 1997b) but, as yet, no relationship between acrosomal status and strength of sperm-zona pellucida binding has been detected (Lynham and Harrison, 1998). The specificity of sperm binding to the zona pellucida in boars has been demonstrated by the blocking of sperm-zona pellucida binding with antibodies against two zona pellucida glycoproteins (Blase et al., 1998). Monoclonal antibodies raised against pig zona pellucida have also been shown to inhibit complete penetration, but not binding, of the canine zona pellucida by canine spermatozoa in an assay in vitro (Bamezai et al., 1988). The acrosomal status of dog spermatozoa bound to the zona pellucida is not known, but data indicate that both acrosomeintact and acrosome-reacted dog spermatozoa are capable of binding to the zona pellucida (Kawakami et al., 1993), and no correlation has been found between acrosomal status and sperm penetration of the oocyte (Hewitt and England, 1998).

The zona pellucida-binding assay protocol used in the present study was the same as that used by Ström Holst et al. (1999), except that the co-incubation time of spermatozoa and oocytes was prolonged from 4 to $6 \mathrm{~h}$. This alteration was made because of the longer capacitation time for fresh semen, compared with for frozen semen, demonstrated by Rota et al. (1999a) using the chlortetracycline assay and CCM. In the present study, the spermatozoa were separated using Percoll density-gradient fractionation. With this method, spermatozoa are separated from foreign material, such as extender particles, cells and bacteria (Rodriguez-Martinez et al., 1997). Washing is important, especially when evaluating extended semen, as, in humans, egg yolk has been shown to have a positive effect on the sperm-zona pellucida-binding capacity (Gamzu et al., 1994) and on in vitro fertility and sperm ultrastructure (Barak et al., 1995).

The egg yolk-Tris extender used in Expt 2 was evaluated for its effect on sperm motility, plasma membrane integrity and acrosomal status by Rota et al. (1995), using a combination of tests in vitro. Rota et al. (1995) report that the mean motility decreased from $73.6 \pm 15.5 \%$ on day 1 to $53.6 \pm 20.1 \%$ on day 4 , and that the percentage of spermatozoa with intact plasma membranes, evaluated using carboxyfluorescein diacetatepropidium iodide (C-FDA/PI), decreased from $80.2 \pm 6.4$ to $72.1 \pm 10.4 \%$. In the present study, the mean number of spermatozoa bound to the zona pellucida was 4.8 on day 1 and 0.9 on day 4 (back-transformed values), which is a decrease of a proportionally greater magnitude than that described for motility and plasma membrane integrity. The results of the present study demonstrate a negative effect of prolonged chilling on the zona pellucida-binding capacity of canine spermatozoa. The large variation within and between replicates demonstrates the diversity in sperm-binding capacity among oocytes and makes it necessary that several replicates are evaluated, as is the case in cattle (Zhang et al., 1995).

In the present study, there were no differences in immediate post-thaw motility between the samples using the extender in the presence or absence of Equex STM paste. This result was in agreement with previous evaluations of the same two extenders (Rota et al., 1997, A. Peña and C. Linde-Forsberg, in press). However, Rota et al. (1997) and A. Peña and C. Linde-Forsberg (in press) demonstrated a significantly higher motility and a higher proportion of spermatozoa with intact plasma membranes during incubation at $38^{\circ} \mathrm{C}$ with EYT-GE than with EYT-G. In the present study, there was a significant beneficial effect of the addition of Equex STM paste on sperm-binding capacity, indicating a beneficial effect also on the molecular structures involved in binding to the zona pellucida. When the fertility in vivo of semen frozen using the same two extenders was evaluated, no significant difference was demonstrated, either after intra-uterine or after vaginal deposition, using five bitches from each group (Rota et al., 1999b). This lack of agreement between fertility characteristics of spermatozoa in vivo and in vitro may reflect the lack of difference in the fertility in vivo of semen frozen using the two types of extenders. However, it is more likely that a difference in fertility in vivo is not detected in a small number of bitches with well-timed inseminations and a relatively large number of spermatozoa (two inseminations of 200 million).

In conclusion, there was a non-significant trend for fewer spermatozoa to bind after storage for 4 days than after storage for 1 day at $4^{\circ} \mathrm{C}$. The addition of Equex STM paste to an egg yolk-Tris extender had a significant positive effect on 
sperm-zona pellucida-binding after freeze-thawing. As the zona pellucida-binding assay evaluates damage that cannot be detected using other techniques, its addition to other established tests in vitro should give a better estimate of the damage caused by various preservation procedures. This procedure will be of use in the development of new techniques for the chilling and freeze-thawing of dog spermatozoa.

The statistical help from U. Engstrand and the technical assistance of A. Jansson are gratefully acknowledged. The authors would like to thank the Department of Small Animal Clinical Sciences, SLU, especially L. Abersten, M. Ederoth and A. Gerentz Bohlin, for providing ovaries.

\section{References}

Amann RP (1989) Can the fertility potential of a seminal sample be predicted accurately? Journal of Andrology 10 89-98

Bamezai AK, Mahi-Brown CA and Talwar GP (1988) Inhibition of penetration of canine zonae pellucidae by homologous spermatozoa in vitro using monoclonal antibodies raised against porcine zonae Journal of Reproductive Immunology 13 85-95

Bane A (1952) A study on the technique of hemocytometric determination of sperm motility and sperm concentration in bull semen Cornell Veterinarian 42 518-531

Barak Y, Bartoov B, Lessing JB, Eltes F, Zabludovsky N and Amit A (1995) Ultrastructural changes in sperm with improved fertilizability after treatment with egg yolk Fertility and Sterility 63 148-152

Berger T, Anderson DL and Penedo MCT (1996) Porcine sperm fertilizing potential in relationship to sperm functional capacities Animal Reproduction Science 44 231-239

Blase N, Fazeli AR, Topper E, Bevers MM, Woelders H, Töpfer-Petersen E, and Colenbrander B (1998) Inhibition of boar sperm binding to homologous zona pellucida by antibodies against ZP3 $\alpha$ and ZP3 $\beta$ glycoproteins Reproduction in Domestic Animals 33 21-25

Codde JM and Berger T (1995) In vivo fertility of rams in relation to sperm-zona pellucida binding and sperm-zona pellucida penetration of ovine oocytes Theriogenology 44 901-906

Fazeli AR, Steenweg W, Bevers MM, de Loos FAM, van den Broek J and Colenbrander B (1993a) Development of a sperm zona pellucida binding assay for bull semen Veterinary Record 132 14-16

Fazeli AR, Steenweg W, Bevers MM, Bracher V, Parlevliet J and Colenbrander B (1993b) Use of sperm binding to homologous hemizona pellucida to predict stallion fertility Equine Veterinary Journal Supplement 15 57-59

Fazeli AR, Holt C, Steenweg W, Bevers MM, Holt WV and Colenbrander B (1995) Development of a sperm hemizona binding assay for boar semen Theriogenology 44 17-27

Fazeli AR, Zhang BR, Steenweg W, Larsson B, Bevers MM, van den Broek J, Rodriguez-Martinez H and Colenbrander B (1997a) Relationship between sperm-zona pellucida binding assays and the 56-day nonreturn rate of cattle inseminated with frozen-thawed bull semen Theriogenology 48 853-863

Fazeli AR, Hage WJ, Cheng F-P, Voorhout WF, Marks A, Bevers MM and Colenbrander B (1997b) Acrosome-intact boar spermatozoa initiate binding to the homologous zona pellucida in vitro. Biology of Reproduction 56 430-438

Franken DR (1998) New aspects of sperm-zona pellucida binding Andrologia $30263-268$

Franken DR, Kruger TF, Oehninger S, Coddington CC, Lombard C, Smith K and Hodgen GD (1993) The ability of the hemizona assay to predict human fertilization in different and consecutive in vitro fertilization cycles Human Reproduction 8 1240-1244

Gamzu R, Yavetz H, Lichtenberg D, Paz G, Homonnai ZT and Yogev Y (1994) The effect of egg yolk on the binding capacity of human spermatozoa to zona pellucida Fertility and Sterility 62 1221-1225

Goodrowe KL and Hay M (1993) Characteristics and zona binding ability of fresh and cooled domestic cat epididymal spermatozoa Theriogenology 40 967-975

Hay MA, King WA, Gartley CJ, Leibo SP and Goodrowe KL (1997a) Effects of cooling, freezing and glycerol on penetration of oocytes by spermatozoa in dogs Journal of Reproduction and Fertility Supplement 51 99-108

Hay MA, King WA, Gartley CJ, Leibo SP and Goodrowe KL (1997b) Canine spermatozoa - cryopreservation and evaluation of gamete interaction Theriogenology 48 1329-1342

Hewitt DA and England GC (1998) The canine oocyte penetration assay; its use as an indicator of dog spermatozoal performance in vitro. Animal Reproduction Science 50 123-139

Ivanova M, Mollova M, Ivanova-Kicheva MG, Petrov M, Djarkova TS and Somlev B (1999) Effect of cryopreservation on zona-binding capacity of canine spermatozoa in vitro. Theriogenology 52 163-170

Kawakami E, Vandevoort CA, Mahi-Browm CA and Overstreet JW (1993) Induction of acrosome reactions of canine sperm by homologous zona pellucida Biology of Reproduction 48 841-845

Lynham JA and Harrison RAP (1998) Use of stored pig eggs to assess boar sperm fertilizing functions in vitro. Biology of Reproduction 58 539-550

Magerkurth C, Töpfer-Petersen E, Schwartz P and Michelmann HW (1999) Scanning electron microscopy analysis of the human zona pellucida: influence of maturity and fertilization on morphology and sperm binding pattern Human Reproduction 14 1057-1066

Mahi-Brown CA (1991) Fertilization in dogs. In A Comparative Overview of Mammalian Fertilization pp 281-297 Eds BS Dunbar and MG O'Rand. Plenum Press, New York

Mahi CA and Yanagimachi R (1978) Capacitation, acrosome reaction, and egg penetration by canine spermatozoa in a simple defined medium Gamete Research 1 101-109

Mayenco-Aguirre AM and Pérez Cortés AB (1998) Preliminary results of hemizona assay (HZA) as a fertility test for canine spermatozoa Theriogenology 50 195-204

Peña A and Linde-Forsberg C Effects of Equex, one- or two-step dilution and two freezing and thawing rates on post-thaw survival of dog spermatozoa Theriogenology (in press)

Rodriguez-Martinez H, Larsson B and Pertoft H (1997) Evaluation of sperm damage and techniques for sperm clean-up Reproduction Fertility and Development 9 297-308

Rota A, Ström B and Linde-Forsberg C (1995) Effects of seminal plasma and three extenders on canine semen stored at $4^{\circ} \mathrm{C}$ Theriogenology $44885-900$

Rota A, Ström B, Linde-Forsberg C and Rodriguez-Martinez H (1997) Effects of Equex STM paste on viability of frozen-thawed dog spermatozoa during in vitro incubation at $38^{\circ} \mathrm{C}$ Theriogenology $471093-1101$

Rota A, Peña AI, Linde-Forsberg C and Rodriguez-Martinez H (1999a) In vitro capacitation of fresh, chilled and frozen-thawed dog spermatozoa as assessed by the chlortetracycline assay and changes in motility patterns Animal Reproduction Science 57 199-215

Rota A, Iguer-Ouada M, Verstegen J and Linde-Forsberg C (1999b) Fertility after vaginal or uterine deposition of dog semen frozen in a Tris extender with or without Equex STM paste Theriogenology 51 1045-1058

Royston JP (1982) An extension of Shapiro and Wilk's test for normality to large samples Applied Statistics 31 591-611

Ström B, Rota A and Linde-Forsberg C (1997) In vitro characteristics of canine spermatozoa subjected to two methods of cryopreservation Theriogenology 48 247-256

Ström Holst B, Rota A, Andersen Berg K, Linde-Forsberg C and RodriguezMartinez H (1998) Canine sperm damage after freezing-thawing: ultrastructural evaluation and content of selected elements Reproduction in Domestic Animals 33 77-82

Ström Holst B, Larsson B, Linde-Forsberg C and Rodriguez-Martinez H (1999) Sperm binding capacity and ultrastructure of the zona pellucida of stored canine oocytes Journal of Reproduction and Fertility 119 77-88

Topper EK, Killian GJ, Way A, Engel B and Woelders H (1999) Influence of capacitation and fluids from the male and female genital tract on the zona binding ability of bull spermatozoa Journal of Reproduction and Fertility 115 175-183

Yanagimachi R (1994) Mammalian fertilization. In The Physiology of Reproduction pp 189-315 Eds E Knobil and J Neill. Raven Press, New York

Zhang BR, Larsson B and Rodriguez-Martinez H (1995) Influence of batches of bovine oocytes on the outcome of an intact zona pellucida binding assay and in vitro fertilization International Journal of Andrology 18 213-220

Zhang BR, Larsson B, Lundeheim N and Rodriguez-Martinez H (1998) Sperm characteristics and zona pellucida binding in relation to field fertility of frozen-thawed semen from dairy AI bulls International Journal of Andrology 21 207-216

Zhang BR, Larsson B, Lundeheim N, Håård MGH and Rodriguez-Martinez H (1999) Prediction of bull fertility by combined in vitro assessments of frozen-thawed semen from young dairy bulls entering an AI-program International Journal of Andrology 22 253-260 